\title{
Analytical modeling of three-stage inactivation of viruses within droplets and solid porous particles
}

\section{Fikret Alic ${ }^{\mathrm{a}}(\mathbb{D}$}

Department of Thermal and Fluid Technique, Faculty of Mechanical Engineering Tuzla, University of Tuzla, Tuzla, Bosnia and Herzegovina

Received: 3 February 2021 / Accepted: 7 June 2021

(C) The Author(s), under exclusive licence to Società Italiana di Fisica and Springer-Verlag GmbH Germany, part of Springer Nature 2021

\begin{abstract}
Various viruses can hide within fluid and solid structures and thus successfully cross different distances, causing the spread of viral infections. Analytical modeling of the triple treatment of virus within a small liquid droplet and within a solid porous particle is the basic research polygon of this paper. The three-stage treatment aims to maximize the efficacy of deactivating viruses indoors. In order to achieve this, viruses undergo treatment by infrared heating, ultraviolet deactivation and ionization-electrostatic deactivation by negative ions. When the droplets are treated with infrared heating, incomplete evaporation occurs, reducing their initial diameter by 10 times; an initial diameter of droplets is $0.01 \mathrm{~mm}, 0.03 \mathrm{~mm}$ and $0.05 \mathrm{~mm}$. Thermal inactivation of viruses inside the droplets is almost negligible, due to short exposure time and a maximum temperature of $100{ }^{\circ} \mathrm{C}$. On the other hand, when solid porous particles are heated to a much higher temperature at the same exposure time, this causes significant thermal inactivation of viruses inside them. Reducing the diameter of the droplet (due to evaporation) by 10 times causes a multiple increase in UV-C deactivation of viruses inside the droplets. The effect of UV-C radiation on viruses within solid porous particles is not included in this paper.
\end{abstract}

\section{List of symbols}

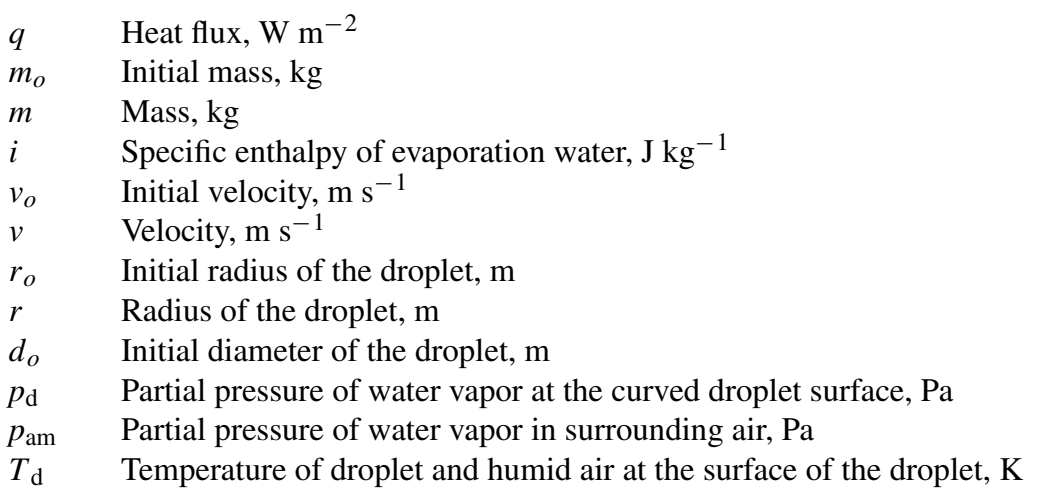

\footnotetext{
a e-mail: fikret.alic@untz.ba (corresponding author)
} 
$T_{\text {am }} \quad$ Temperature of the surrounding air, $\mathrm{K}$

$D_{\mathrm{w}} \quad$ Water diffusion coefficient, $\mathrm{m}^{2} \mathrm{~s}^{-1}$

$R_{\mathrm{u}} \quad$ Universal gas constant, $\mathrm{J} \mathrm{k} \mathrm{mol}{ }^{-1} \mathrm{~K}^{-1}$

$M_{\mathrm{w}} \quad$ Relative molecular mass of the water, $\mathrm{kg} \mathrm{k} \mathrm{mol}^{-1}$

$\rho_{\mathrm{d}} \quad$ Density of the water droplet, $\mathrm{kg} \mathrm{m}^{-3}$

$p_{\text {sat }} \quad$ Saturated vapor pressure above flat surface, $\mathrm{Pa}$

$\sigma_{d} \quad$ Liquid/vapor surface tension, $\mathrm{N} \mathrm{m}^{-1}$

$C_{\mathrm{D}} \quad$ Drag coefficient, -

Re Reynolds number, -

$\Delta v \quad$ Change velocity, $\mathrm{m} \mathrm{s}^{-1}$

$\Delta m \quad$ Change mass, $\mathrm{kg}$

$C_{x} \quad$ Concentration of viruses on point $x, \mathrm{~kg} \mathrm{~m}^{-3}$

$C_{x+\Delta x}$ Concentration of viruses on point $x+\Delta x, \mathrm{~kg} \mathrm{~m}^{-3}$

$C_{o} \quad$ Initial concentration of viruses, $\mathrm{kg} \mathrm{m}^{-3}$

$C \quad$ Concentration of viruses, $\mathrm{kg} \mathrm{m}^{-3}$

$u \quad$ Axial velocity, $\mathrm{m} \mathrm{s}^{-1}$

$T \quad$ Temperature, $\mathrm{K}$

$m \quad$ Mass flow, $\mathrm{kgs}^{-1}$

$c_{\mathrm{W}} \quad$ Mass concentration of water vapor, $\mathrm{kg} \mathrm{m}^{-3}$

$D_{\mathrm{w}} \quad$ Diffusion coefficient for water vapor in the air, $\mathrm{m}^{2} \mathrm{~s}^{-1}$

$R \quad$ Radius of UV-C chamber, $\mathrm{m}$

$R_{\mathrm{L}} \quad$ Radius of germicidal lamp, m

I Intensity of UVGI source, $\mathrm{W} \mathrm{m}^{-2}$

$D_{\mathrm{UV}} \quad$ Dose of UV-C, $\mathrm{J} \mathrm{m}^{-2}$

$L_{\mathrm{L}} \quad$ Length of UVGI lamp, m

a Albedo, -

$n \quad$ Refractive index, -

$d_{\mathrm{p}} \quad$ Particle diameter, $\mathrm{m}$

$m_{\mathrm{p}} \quad$ Particle mass, $\mathrm{kg}$

$C_{\text {Cun }} \quad$ Cunningham's correction factor, -

$r_{+} \quad$ Radius of the positive electrode, $\mathrm{m}$

$r_{-} \quad$ Radius of the negative electrode, $\mathrm{m}$

$F_{\text {el }} \quad$ Force of the electrical field, N

$v_{\mathrm{r}} \quad$ Radial velocity, $\mathrm{m} \mathrm{s}^{-1}$

\section{Greek symbols}

$\tau$ Time, $\mathrm{s}$

$\gamma$ Geometrical ratio, -

$\mu$ Dynamic viscosity, $\mathrm{Pa} \mathrm{s}$

$\rho \quad$ Density, $\mathrm{kg} \mathrm{m}^{-3}$

$\beta$ Velocity ratio, -

$\sigma \quad$ Stefan-Boltzmann constant, $\mathrm{W} \mathrm{m}^{-2} \mathrm{~K}^{-4}$

$\varphi \quad$ Mass ratio, -

$q_{\mathrm{el}}$ Electrical charge, $\mathrm{C}$

$\varepsilon \quad$ Dielectric constant of the particle, -

$\varepsilon_{o} \quad$ Dielectric permittivity of the vacuum, $\mathrm{C}^{2} \mathrm{~N}^{-1} \mathrm{~m}^{-2}$ 


\section{Introduction}

The rapid spread of coronavirus (SARS-CoV-2) shows that physical interpretations of virus transport indoors and outdoors are not the clearest. Coughing, sneezing and even speech are accompanied by the desorption of droplets of different dimensions that move at different speeds through the air. The distance traveled by droplets is usually up to $2 \mathrm{~m}$, and smaller droplets travel further than larger droplets. The subject of many analyses and studies, for example [1-3], referred to the dispersion of liquid droplets during coughing and sneezing, which directly lead to the spread of the virus from infected persons. The reason for the different path lengths depends on the initial kinetic energy of the droplet, as well as on the forces of aerodynamic air resistance between the droplet and the ambient air. Accordingly, the viruses are transmitted by droplets and thus spread in the area around the person infected with this virus. Some authors have conducted modeling of the droplet evaporation and sedimentation, resulting from speaking and coughing, such as [4-6]. Today, there are several ways to prevent the spread of viruses, which have different efficiencies, according to the type of viruses and the parameters of the environment in which they are found. One of the ways to disable various viruses is thermal inactivation. Many researchers have performed analyses of the thermal treatment of various viruses and microorganisms of the coronavirus, such as [7-11]. On the other hand, thermal inactivation of the coronavirus, SARS-CoV, has also been the research site of several researchers, e.g., $[12,13]$. One way to deactivate coronavirus is to use ultraviolet light (UV-C). For the deactivation of various viruses, UV germicidal lamps are most often used, which emit a wavelength of ultraviolet waves in the amount of $254 \mathrm{~nm}$. Different selective inactivations of the virus by the action of UV-C radiation, i.e., Ultraviolet Germicidal Irradiation (UVGI), using a germicidal lamp have been the subject of research by various researchers [14-18]. On the other hand, the impact of negative ions on human health and the air quality that people breathe was investigated by many authors, such as [19-21]. When it comes to the effect of negative ions on various viruses and the prevention of their transmission, there are many studies and analyses [22-24]. In this paper, the focus is on the triple deactivation treatment of two types of viruses those within liquid droplets and those within porous solid particles. The first type is contained in tiny droplets that are found in enclosed spaces and can occur in a variety of ways, forcibly or naturally. The entry of the free virus into the droplet can occur under different physical conditions, and this is not the subject of research in this paper. This analysis does not cover the way the virus entered inside a droplet or porous particle. The efficiency of the proposed solution of three-stage inactivation of the virus will be higher if the accumulation of viral particles on the droplet surface is taken into account, and if the viruses have become hydrophobic for any reason. Reasons that may cause the hydrophilic virus to become partially or completely hydrophobic are uncovered by this analysis. There are many studies about the colloid retention on air-water interface, which has been also applied to viral particles. Inactivation of accumulated viruses on the droplet surface is not covered by this paper. Some studies have analyzed in detail the accumulation of viral particles on the droplet surface, because of viral particle hydrophobicity [25-27]. The very small dimensions of the virus, on the order of $0.1 \mu \mathrm{m}$, allow it to enter the pores of a solid porous particle. The porous solid particle in this way provides transport to the virus, through the ambient air. In order to ensure successful deactivation of viruses, an innovative three-stage deactivation system is established in this paper. The three-component system consists of an infrared heating chamber, a chamber with ultraviolet radiation and an ionization-separation chamber. The purpose of the infrared heating chamber is to evaporate the droplets and heat the porous solid particles by thermal radiation in the infrared region. The first virus is in the droplet, while the second virus is inside the porous solid particle 
entering the first chamber, with infrared thermal heating. Inside this chamber, the diameter of the droplet is reduced several times due to evaporation, while the solid porous particle is heated, but the dimensions do not change. In the next chamber, ultraviolet inactivation of the virus contained inside the droplet occurs. The effect of ultraviolet radiation on the virus within the porous solid particle is not included in this paper. The third (last) chamber contains ionization-separation subchambers. In the first ionization subchamber, the virus is deactivated within the porous particle by the action of negative ions. In the separation chamber, the deactivated virus together with the porous particle separates and stops at the electrodes.

\section{Combined treatment of viruses}

The initial diameters of the droplet and the porous particle are the same and have equal $d_{o}$, while their initial velocity is $v_{o}$. The term initial velocity means the velocity immediately before entering the three-component system for the treatment of viruses. The purpose of the infrared heating chamber is to evaporate the droplets and heat the porous solid particles by thermal radiation in the infrared region. When the droplet hiding the virus is heated, the diameter of the droplet decreases due to the evaporation of the droplet liquid. With this treatment, the virus is no longer hidden and there is a possibility that it can be effectively treated in the next chamber. On the other hand, infrared heating of a porous solid particle causes an increase in its temperature. In the next stage, the virus and the particle enter a chamber with ultraviolet radiation, within which UV-C radiation acts on the free virus and inactivates it by acting on the thymine inside the DNA molecule. The effect of UV-C radiation on the virus within the porous solid particle is not addressed in this paper. An inactivated free virus and a porous particle in which the virus is hidden come out of the ultraviolet chamber. The ionization-separation chamber is a space for the final treatment of viruses, and it consists of two subprocesses. The first subprocess involves electrostatic isolation of a porous particle and deactivated free virus. In this way, negative ions come into direct contact with the surface of the virus and inactivate it. By the action of the electric field force, the porous particle and the deactivated free virus begin to move radially in the direction of the separation positive electrodes, where they accumulate in the form of micro-dust. Removal of harmless micro-dust is achieved in several mechanical ways or by blowing, which goes beyond the application of the methodology in this paper. The described procedure treated two viruses hidden in a liquid droplet and a porous solid particle, but it is clear that the whole process also applies to more viruses.

\section{Thermal analysis of liquid droplets and solid porous particles}

The effect of high temperature on viruses is generally unfavorable, while the sensitivity of viruses to high temperatures depends on:

- Temperature height;

- Duration of virus exposure time to high temperature;

- The type of media in which the virus is located;

- Protein sensitivity;

- RNA sensitivity. 
When heated, most viruses lose their ability to reproduce, along with their infectious power, antigenicity and immunogenicity. The thermal analysis covered by this research is focused in two directions:

- Reducing the volume of the droplet in which the virus is hidden by infrared heating;

- Infrared heating of a solid porous particle inside which the virus is located.

\subsection{Thermal analysis: reduction of droplet volume}

During coughing, sneezing or talking, drops of different diameters and speeds come out of people's mouths and noses. If a person is infected, the droplets ensure its spread into the ambient air. Smaller droplets are lighter, and their path through the air is longer. The larger the droplets, the larger is their weight, the sooner they will fall. Droplets of different sizes fall on different surfaces, where they can remain for a long time. The droplet enters the annular channel with the central infrared heat source installed, as shown in Fig. 1. The droplet is approximated by a sphere of initial diameter $d_{o}$ and density $\rho$, while its initial velocity is $v_{o}$. It is assumed that the heat flux from a cylindrical infrared heat source is a constant amount $q$. The heat flux enters the droplet through its outer surface of the initial radius $r_{o}$ and is completely absorbed in it. Due to the absorption of heat, the liquid part of the droplet evaporates, and thus, the mass of the droplet changes during time $\tau$, Eq. (1),

$$
2\left(q r_{0}^{2} \pi\right)=i \frac{\mathrm{d} m}{\mathrm{~d} \tau}=i \rho \frac{4 r^{2} \pi}{\mathrm{d} \tau} \mathrm{d} r
$$

where $i$ is the specific latent heat of evaporation of liquid. Due to the thermal influence, i.e., heating, the radius of the spherical droplets decreases, so at some point in time it is $r=r_{o}-\mathrm{d} r$, so by reorganizing Eq. (1) we get

$$
q(r+\mathrm{d} r)^{2} \mathrm{~d} \tau=2 i \rho r^{2} \mathrm{~d} r
$$

that is, after neglecting the square term $\mathrm{d} r^{2}$

$$
q\left(r^{2}+2 r \mathrm{~d} r+\mathrm{d} r^{2}\right) \mathrm{d} \tau \approx q\left(r^{2}+2 r \mathrm{~d} r\right) \mathrm{d} \tau=2 i \rho r^{2} \mathrm{~d} r
$$

by sorting the variables and integrating it is obtained

$$
q\left(r_{0}^{2}-r^{2}\right) \tau+q\left(r_{0}^{2}-r^{2}\right) \tau=\frac{2}{3} i \rho\left(r_{0}^{3}-r^{3}\right)
$$

from which the time of thermal exposure $\tau$ of the droplet to infrared radiation is explicitly found

$$
\tau=\frac{1}{3} \frac{i \rho}{q} \frac{\left(r_{0}^{3}-r^{3}\right)}{\left(r_{0}^{2}-r^{2}\right)}=\frac{1}{3} \frac{i \rho}{q} \frac{\left(r_{0}^{2}+r_{0} r+r^{2}\right)}{\left(r_{0}+r\right)} .
$$

The previous expression can also be represented in a form

$$
\tau=\frac{1}{3} \frac{i \rho r_{0}}{q} \frac{\left(1+\gamma+\gamma^{2}\right)}{(1+\gamma)}
$$

where geometrical ratio is $\gamma$

$$
\gamma=\frac{d_{0}}{d}=\frac{r_{0}}{r}
$$

A spherical droplet moves inside the thermal field of an infrared cylindrical heater, whereby both its mass and its velocity change. 


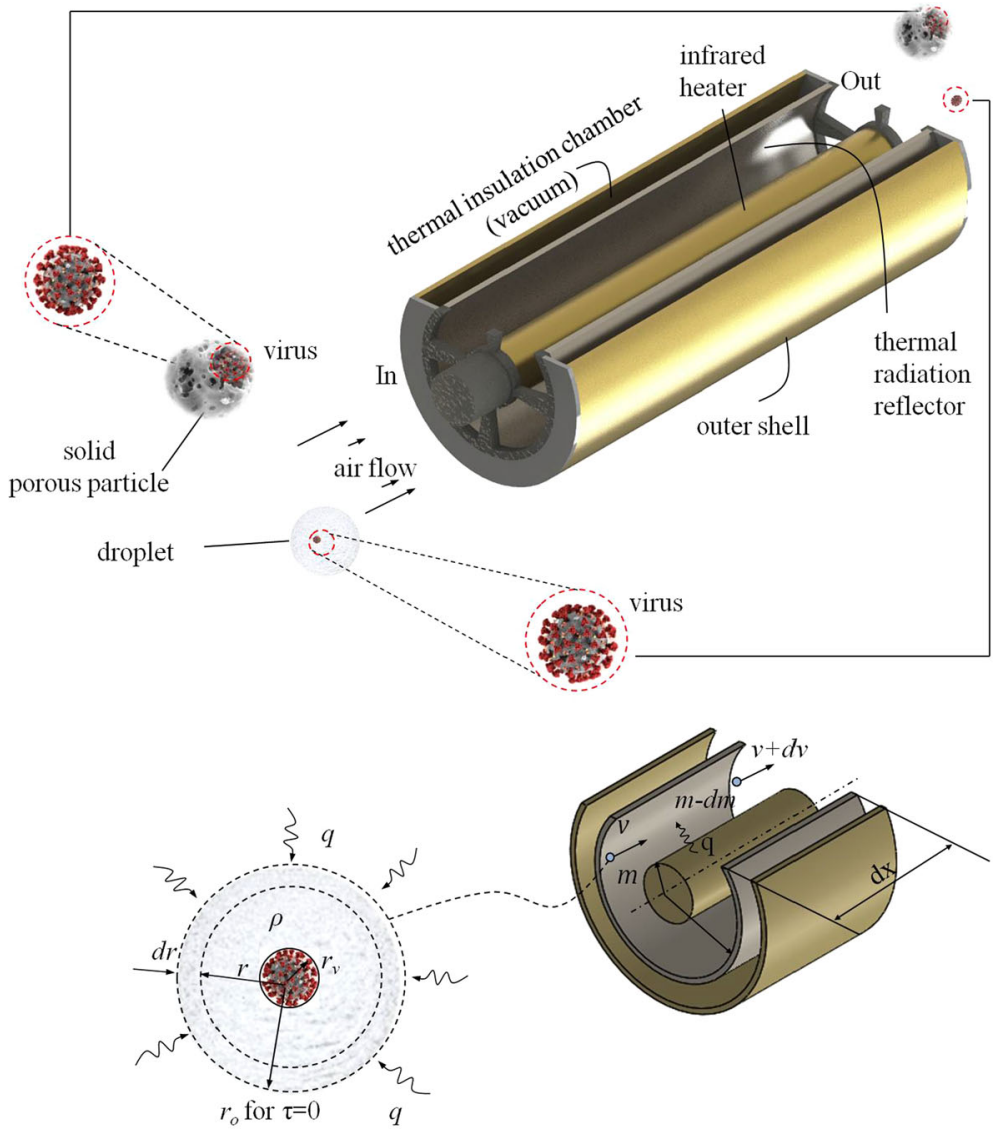

Fig. 1 Thermal treatment of viruses inside a solid porous particle and viruses inside liquid droplets. Reduction of droplet diameter due to evaporation by infrared

The movement of the droplet is opposed by the friction force, so the balance of all forces is represented by Eq. (8). The left term of Eq. (8) represents the differential change of amount of movement per unit of time, the change in speed and mass,

$$
\frac{\mathrm{d}(m v)}{\mathrm{d} \tau_{d}}=m \frac{\mathrm{d} v}{\mathrm{~d} \tau_{d}}+v \frac{\mathrm{d} m}{\mathrm{~d} \tau_{d}}=m \frac{18 \mu_{1}}{\rho_{\mathrm{l}} d^{2}} \frac{C_{\mathrm{D}} v}{24} \operatorname{Re}
$$

where $C_{\mathrm{D}}$ is drag coefficient, Re is Reynolds number, and $\mu$ is dynamic viscosity of the air.

The drag coefficient is $C_{\mathrm{D}}=0.44$ for Reynolds number of $1000<$ Re. After arranging Eq. (8), it follows

$$
\frac{\mathrm{d} v}{v}+\frac{\mathrm{d} m}{m}=\frac{3}{4} \frac{\mu_{l}}{\rho_{l}} \frac{C_{\mathrm{D}}}{d^{2}} \operatorname{Re} d \tau_{d}
$$

where $\beta$ is introduced, as the ratio of the velocities of the spherical droplet at the initial moment $v_{o}$ in relation to the velocity of the droplet $v$ after the time $\tau$, Eq. (10).

$$
\beta=\frac{v_{0}}{v}
$$


The parts of Eq. (9) on the left side can be observed as relative changes in the velocities of the droplet and its mass, respectively, Eqs. (11) and (12).

$$
\begin{gathered}
\frac{\Delta v}{v}=\frac{v_{0}-v}{v}=\beta-1 \\
\frac{\Delta m}{m}=\frac{m_{0}-m}{m}=\left(\frac{r_{0}}{r}\right)^{3}-1=\gamma^{3}-1
\end{gathered}
$$

Combining Eqs. (11) and (12) with Eq. (9) gives

$$
(\beta-1)+\left(\gamma^{3}-1\right)=\frac{3}{4} \frac{\mu_{l}}{\rho_{l}} \frac{\rho_{f}}{\mu_{f}} \frac{0.44 \gamma^{2}}{d_{0}} \frac{v_{0}}{\beta \gamma} \tau_{d}
$$

which after arranging is reduced to the quadratic equation, by $\beta$, Eq. (14).

$$
\beta^{2}+\left(\gamma^{3}-2\right) \beta-0.33 \frac{\mu_{l}}{\mu_{f}} \frac{\rho_{f}}{\rho_{l}} \frac{v_{0}}{d_{0}} \gamma \tau_{d}=0
$$

Solving Eq. (14) yields the final expression for the ratio of the change speed of the liquid droplets during the time $\tau_{d}$ and the ratio $\gamma$,

$$
\beta=\frac{-\left(\gamma^{3}-2\right)+\left[\left(\gamma^{3}-2\right)^{2}+1.32 \frac{\mu_{l}}{\mu_{f}} \frac{\rho_{f}}{\rho_{l}} \frac{v_{0}}{d_{0}} \gamma \tau_{d}\right]^{0.5}}{2}
$$

and after combining Eq. (15) with Eq. (10), the expression for changing the velocity of the droplet as a function of the ratio $\gamma$ is

$$
\Delta v=a \tau_{d}=\frac{2\left(L_{\mathrm{Ic}}-v_{o} \tau_{d}\right) \tau_{d}}{\tau_{d}^{2}}=v_{o}\left\{\frac{2}{-\left(\gamma^{3}-2\right)+\left[\left(\gamma^{3}-2\right)^{2}+1.32 \frac{\mu_{l}}{\mu_{f}} \frac{\rho_{f}}{\rho_{l}} \frac{v_{0}}{d_{0}} \gamma \tau_{d}\right]^{0.5}}-1\right\}
$$

that is, the expression for the length of the infrared heater $L_{I C}$,

$$
L_{\mathrm{Ic}}=v_{o} \tau_{d}+\frac{v_{o} \tau_{d}}{2}\left\{\frac{2}{-\left(\gamma^{3}-2\right)+\left[\left(\gamma^{3}-2\right)^{2}+1.32 \frac{\mu_{l}}{\mu_{f}} \frac{\rho_{f}}{\rho_{l}} \frac{v_{0}}{d_{0}} \gamma \tau_{d}\right]^{0.5}}-1\right\} .
$$

\subsection{Mass balance of the droplet}

The mass flow rate of water vapor from the droplet represents the transition of mass flux from the surface of the droplet into the ambient air, as shown in Fig. 2, according to Fick's law and has the form,

$$
\dot{m}_{\mathrm{w}}=-A_{\mathrm{d}} D_{\mathrm{w}} \frac{\mathrm{d} C_{\mathrm{w}}}{\mathrm{d} r}=-4 r^{2} \pi D_{\mathrm{w}} \frac{\mathrm{d} C_{\mathrm{w}}}{\mathrm{d} r}
$$

where $c_{\mathrm{w}}$ is the mass concentration of water vapor, and $r$ is the radius of the droplet, while $D_{\mathrm{w}}$ is the diffusion coefficient for water vapor in the air.

After separating the variables

$$
\int_{r_{d}}^{r_{\mathrm{am}}} \dot{m}_{\mathrm{w}} \frac{\mathrm{d} r}{r^{2}}=-4 \pi \int_{c_{\mathrm{rd}}}^{c_{\mathrm{am}}} D_{\mathrm{w}} \mathrm{d} C_{\mathrm{w}}
$$

and after integrating the expression, a mass flow rate of water vapor from the droplet is obtained

$$
\dot{m}_{\mathrm{w}}=\frac{4 \pi D_{\mathrm{w}}\left(c_{\mathrm{rd}}-c_{\mathrm{am}}\right)}{\frac{1}{r_{\mathrm{d}}}-\frac{1}{r_{\mathrm{am}}}}=4 \pi r_{\mathrm{d}} D_{\mathrm{w}}\left(c_{\mathrm{rd}}-c_{\mathrm{am}}\right)
$$




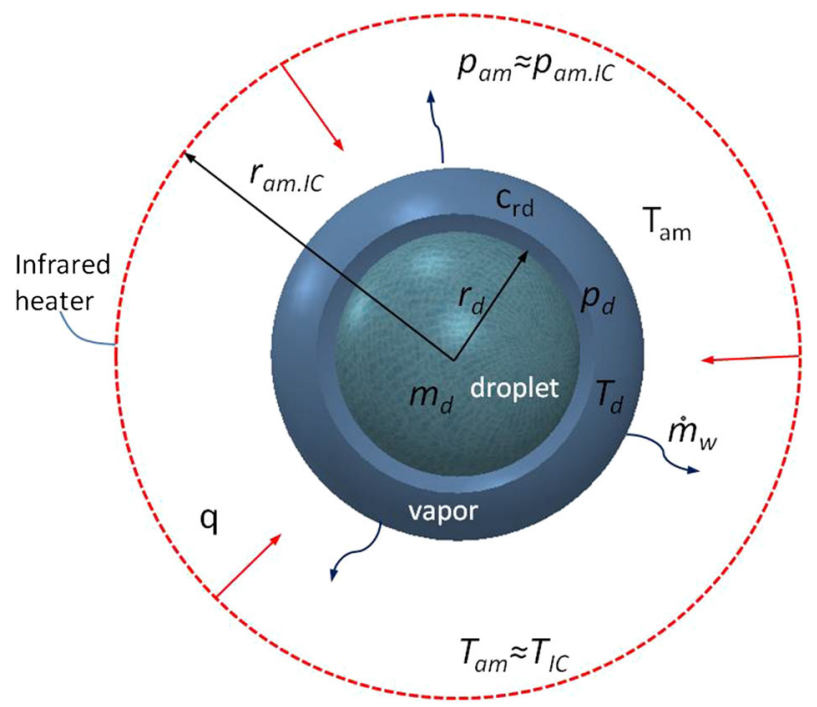

Fig. 2 Mass water vapor transfer from droplet surface

where $r_{\mathrm{d}}$ is droplet radius, $r_{\mathrm{am}}$ is some distance away from the droplet surface, $c_{\mathrm{rd}}$ is mass concentration of water vapor at the droplet surface, and $c_{\mathrm{am}}$ is mass concentration of water vapor at some distance away from the droplet surface.

If an approximation is introduced that water vapor has the properties of an ideal gas, then the application of the gas state equation follows

$$
\dot{m}_{\mathrm{w}}=4 \pi r_{\mathrm{d}} D_{\mathrm{w}}\left(\frac{p_{\mathrm{d}} M_{\mathrm{w}}}{R_{\mathrm{u}} T_{\mathrm{d}}}-\frac{p_{\mathrm{am}} M_{\mathrm{w}}}{R_{\mathrm{u}} T_{\mathrm{am}}}\right)=4 \pi r_{\mathrm{d}} D_{\mathrm{w}} \frac{M_{\mathrm{w}}}{R_{\mathrm{u}}}\left(\frac{p_{\mathrm{d}}}{T_{\mathrm{d}}}-\frac{p_{\mathrm{am}}}{T_{\mathrm{am}}}\right)
$$

where $p_{\mathrm{d}}$ and $p_{\mathrm{am}}$ are partial pressure of water vapor at the curved droplet surface and in surrounding air, respectively. The temperature of the droplet and humid air at the surface of the droplet is $T_{\mathrm{d}}$, while $T_{\mathrm{am}}$ is the temperature of the surrounding air. On the other hand, the mass production of water vapor represents a decrease in the mass of the water droplet over time; that is, it is a valid next equation.

$$
\dot{m}_{\mathrm{w}}=\frac{\mathrm{d} m_{\mathrm{d}}}{\mathrm{d} \tau}=\frac{\mathrm{d}}{\mathrm{d} \tau}\left(\rho_{\mathrm{d}} \frac{4}{3} r_{\mathrm{d}}^{3} \pi\right)=4 \pi r_{\mathrm{d}} D_{\mathrm{w}} \frac{M_{\mathrm{w}}}{R_{\mathrm{u}}}\left(\frac{p_{\mathrm{d}}}{T_{\mathrm{d}}}-\frac{p_{\mathrm{am}}}{T_{\mathrm{am}}}\right)
$$

After arranging the previous equation, we get the expression for changing the radius of the droplet as a function of time, Eqs. (23) and (24),

$$
r_{\mathrm{d}} \mathrm{d} r=D_{\mathrm{w}} \frac{M_{\mathrm{w}}}{R_{\mathrm{u}} \rho_{\mathrm{d}}}\left(\frac{p_{\mathrm{d}}}{T_{\mathrm{d}}}-\frac{p_{\mathrm{am}}}{T_{\mathrm{am}}}\right) \mathrm{d} \tau
$$

and after integration, it is finally obtained

$$
\frac{r_{\mathrm{do}}^{2}}{2}-\frac{r_{\mathrm{d}}^{2}}{2}=D_{\mathrm{w}} \frac{M_{\mathrm{w}}}{R_{\mathrm{u}} \rho_{\mathrm{d}}}\left(\frac{p_{\mathrm{d}}}{T_{\mathrm{d}}}-\frac{p_{\mathrm{am}}}{T_{\mathrm{am}}}\right) \tau .
$$


where $R_{\mathrm{u}}=8314,47 \mathrm{~J} \mathrm{kmol}^{-1} \mathrm{~K}^{-1}$ is universal gas constant, and $M_{\mathrm{w}}=18 \mathrm{~kg} \mathrm{kmol}^{-1}$ is relative molecular mass of water, while $\rho_{\mathrm{d}}$ is the density of water droplet. Combining Eq. (24) with expression (7) gives

$$
r_{\mathrm{do}}^{2}\left(1-\gamma^{2}\right)=2 D_{\mathrm{w}} \frac{M_{\mathrm{w}}}{R_{\mathrm{u}} \rho_{\mathrm{d}}}\left(\frac{p_{\mathrm{d}}}{T_{\mathrm{d}}}-\frac{p_{\mathrm{am}}}{T_{\mathrm{am}}}\right) \tau
$$

whence the time required to reduce the diameter of the droplet, under the given conditions, $\gamma$ times, is obtained,

$$
\begin{aligned}
\tau= & \frac{r_{\mathrm{do}}^{2}\left(1-\gamma^{2}\right)}{2 D_{\mathrm{w}} \frac{M_{\mathrm{w}}}{R_{\mathrm{u}} \rho_{\mathrm{d}}}\left(\frac{p_{\mathrm{d}}}{T_{\mathrm{d}}}-\frac{p_{\mathrm{am}}}{T_{\mathrm{am}}}\right)}=\frac{r_{\mathrm{do}}^{2}\left(1-\gamma^{2}\right)}{2\left(1.87 \times 10^{-10}+\frac{T^{2.072}}{p}\right) \frac{M_{\mathrm{w}}}{R_{\mathrm{u}} \rho_{\mathrm{d}}}\left[\frac{p_{\mathrm{d}}}{T_{\mathrm{d}}}-\frac{p_{\mathrm{am} \cdot \mathrm{IC}}}{T_{\mathrm{IC}}}\right]} \\
= & \frac{r_{\mathrm{do}}^{2}\left(1-\gamma^{2}\right)}{2\left(1.87 \times 10^{-10}+\frac{T^{2.072}}{p_{\mathrm{am} \cdot \mathrm{IC}}}\right) \frac{M_{\mathrm{w}}}{R_{\mathrm{u}} \rho_{\mathrm{d}}}\left[\frac{p_{\mathrm{sat}} \exp \left(\frac{4 \sigma_{\mathrm{d}} M_{\mathrm{w}} \gamma}{\rho_{\mathrm{d}} R_{\mathrm{u}} r_{\mathrm{d}}\left(T_{\mathrm{IC}}^{4}-\frac{q}{\sigma}\right)^{0.25}}\right)}{\left(T_{\mathrm{IC}}^{4}-\frac{q}{\sigma}\right)^{0.25}}-\frac{p_{\mathrm{am} \cdot \mathrm{IC}}}{T_{\mathrm{IC}}}\right]}
\end{aligned}
$$

where the term used for the diffusion coefficient of water vapor in air is $D_{\mathrm{w}}$, [28], $\mathrm{p}$ is the total pressure, and $T$ is temperature, while $\sigma$ is Stefan-Boltzmann constant. Within expression (26), it is considered that $T_{\mathrm{am}} \approx T_{\mathrm{IC}}$, where $T_{\text {IC }}$ is the temperature of the infrared source, and $p_{\text {am }}$ is partial pressure of water vapor in the surrounding air approximately equal to the pressure near the infrared heater, $p_{\mathrm{am}} \approx p_{\text {am.IC }}$. The droplet temperature $T_{\mathrm{d}}$ changes during heating due to both continuous heating and changes in its dimensions. In this analytical modeling and analysis, the heat flux $q$ from the infrared source to the droplet is kept constant regardless of droplet temperature changes. The partial pressure of water vapor at the curved droplet surface increases its value according to the Kelvin effect, which is used in expression (26). According to the extension of expression (26), $p_{\text {sat }}$ is saturated vapor pressure above a flat surface, while $\sigma_{d}$ is liquid/vapor surface tension.

\subsection{Thermal analysis: heating of a porous solid particle}

When it comes to infrared heating of solid porous particles inside the annular channel, as in the previous case with droplets, a heat balance is established by Eq. (27). The solid particle is approximated by a sphere of radius $r_{o}$ and mass $m_{p}$, which is exposed to thermal radiation from an infrared heat source of temperature $T_{\mathrm{IC}}$. Due to the thermal radiation, the particle is heated to temperature $T(\tau)$ and itself becomes a source of thermal radiation.

$$
2\left(q r_{0}^{2} \pi\right)=2 r_{o}^{2} \pi \sigma\left(T_{\mathrm{IC}}^{4}-T^{4}\right)=m_{p} c_{p} \frac{\mathrm{d} T}{\mathrm{~d} \tau_{p}}=\rho_{p} \frac{4}{3} r_{o}^{3} \pi c_{p} \frac{\mathrm{d} T}{\mathrm{~d} \tau_{p}}
$$

The initial temperature of the particle is equal to the ambient temperature $T_{a m b}$

$$
\frac{3}{2} \frac{\sigma}{\rho_{p} r_{o} c} \int_{0}^{\tau_{p}} \mathrm{~d} \tau_{p}=\int_{T_{\mathrm{amb}}}^{T} \frac{\mathrm{d} T}{T_{I C}^{4}-T^{4}} .
$$


After the integration, the expression for the exposure time $(\tau)$ of the virus is obtained, i.e., the heating time of the porous particle, Eq. (29),

$$
\begin{aligned}
\tau_{p} & =\frac{\mathrm{d}_{o} \rho_{p} c_{p}}{3 \sigma} \int_{T_{\mathrm{amb}}}^{T} \frac{\mathrm{d} T}{T_{\mathrm{IC}}^{4}-T^{4}} \\
& =-\frac{\mathrm{d}_{o} \rho_{p} c_{p}}{3 \sigma} \int_{\mathrm{T}_{\mathrm{amb}}}^{T} \frac{\mathrm{d} T}{T^{4}-T_{\mathrm{IC}}^{4}}=-\frac{\mathrm{d}_{o} \rho_{p} c_{p}}{3 \sigma} \int_{T_{\mathrm{amb}}}^{T} \frac{\mathrm{d} T}{\left(T-T_{\mathrm{IC}}\right)\left(T+T_{\mathrm{IC}}\right)\left(T^{2}+T_{\mathrm{IC}}^{2}\right)} \\
& =-\frac{\mathrm{d}_{o} \rho_{p} c_{p}}{3 \sigma} \int_{T_{\mathrm{amb}}}^{T}\left[-\frac{1}{2 T_{I C}^{2}\left(T^{2}+T_{\mathrm{IC}}^{2}\right)}-\frac{1}{4 T_{\mathrm{IC}}^{3}\left(T+T_{\mathrm{IC}}\right)}+\frac{1}{4 T_{\mathrm{IC}}^{3}\left(T-T_{\mathrm{IC}}\right)}\right] \mathrm{d} T \\
& =-\frac{\mathrm{d}_{o} \rho_{p} c_{p}}{3 \sigma}\left[\left.\frac{\arctan \left(\frac{T}{T_{\mathrm{IC}}}\right)}{2 T_{\mathrm{IC}}^{3}}\right|_{T_{\mathrm{amb}}} ^{T}+\frac{\left.\left.\ln \left(T+T_{\mathrm{IC}}\right)\right|_{T_{\mathrm{amb}}} ^{T}+\frac{\left.\ln \left(T-T_{\mathrm{IC}}\right)\right|_{T_{\mathrm{amb}}} ^{T}}{4 T_{\mathrm{IC}}^{3}}\right] ;}{4 T_{\mathrm{IC}}^{3}}\right]
\end{aligned}
$$

that is, after sorting, the final expression is obtained, Eq. (30).

$$
\tau_{p}=-\frac{\mathrm{d}_{o} \rho_{p} c_{p}}{3 \sigma} \frac{\left[\begin{array}{c}
\ln \left(T+T_{\mathrm{IC}}\right)-\ln \left(T_{\mathrm{amb}}+T_{\mathrm{IC}}\right)+2 \arctan \left(\frac{T}{T_{\mathrm{IC}}}\right)- \\
2 \arctan \left(\frac{T_{\mathrm{amb}}}{T_{\mathrm{IC}}}\right)-\ln \left(T-T_{\mathrm{IC}}\right)+\ln \left(T_{\mathrm{amb}}-T_{\mathrm{IC}}\right)
\end{array}\right]}{4 T_{\mathrm{IC}}^{3}}
$$

\subsection{Thermal inactivation of viruses within droplets and solid porous particles}

The change in the concentration of thermally inactivated viruses, within droplets and solid porous particles, after an exposure time $(\tau)$ can be expressed in differential form,

$$
\frac{\mathrm{d} C}{\mathrm{~d} \tau_{d(p)}}=-k C
$$

where $k$ is the time-dependent parameter due to the variation of temperature and after integration and using the Arrhenius equation for $k(\tau)$ is obtained,

$$
\ln \frac{C}{C_{o}}=-k \tau_{d(p)}=-P \exp \left(-\frac{E_{\mathrm{a}}}{R T}\right) \tau_{d(p)}
$$

where $C$ is virus concentration at time $\tau, C_{o}$ is virus concentration in the initial state, $E_{\mathrm{a}}$ is activation energy, $P$ is collision number or frequency factor, $R$ is universal gas constant, $T$ is absolute temperature, and $\tau$ is time. The efficiency of thermal inactivation of the virus $\eta_{I C}$ due to infrared heating of the droplet and the porous solid particle after combining with Eq. (32) is shown by Eq. (33).

$$
\eta_{\text {IC }}=1-\frac{C}{C_{o}}=1-\exp \left[-P \exp \left(-\frac{E_{\mathrm{a}}}{R T}\right) \tau_{d(p)}\right]
$$

In order for thermal inactivation of viruses within a droplet and in a porous solid particle to occur, the temperature of the droplet and viruses must be higher than the critical temperature, which can be found from the following equation

$$
k=P \exp \left(-\frac{E_{\mathrm{a}}}{R T_{\text {crit }}}\right)=1
$$


that is

$$
T>T_{\text {crit }}=\frac{E_{\mathrm{a}}}{R \ln (P)}
$$

The second condition for thermal inactivation of viruses is that the exposure time must be longer than the critical time, which is achieved from the following equation, i.e.,

$$
\int_{0}^{\tau_{c r i t}} k \mathrm{~d} \tau_{d(p)}=\int_{0}^{\tau_{c r i t}} P \exp \left(-\frac{E_{\mathrm{a}}}{R T}\right) \mathrm{d} \tau_{d(p)}=1,
$$

so it follows

$$
\tau_{d(p)} \geq \tau_{\text {crit }}=\frac{1}{P} \exp \left(\frac{E_{\mathrm{a}}}{R T}\right) .
$$

\section{Ultraviolet treatment of viruses}

Ultraviolet radiation (UV) is classified into three categories, commonly referred to as UV-A, UV-B and UV-C. UV-A (from 320 to $390 \mathrm{~nm}$ ) has the lowest energy level, while UV-C (from 200 to $280 \mathrm{~nm}$ ) has the highest energy level. Ultraviolet UV-C radiation in this wave region is also called Ultraviolet Germicidal Irradiation (UVGI). Most often, a low-pressure mercuryvapor lamp is used to generate UV germicidal light, while recently a xenon lamp that emits a wide range of wavelengths has also been used. UVGI or UV-C is often used to disinfect or destroy various microorganisms and viruses by breaking down their cell membranes and damaging their RNA or DNA. In this way, the damaged RNA structure stops the virus particles from multiplying, making them harmless, as shown in Fig. 3. In order to neutralize, for example, the influenza virus, the energy dose of ultraviolet radiation that enables inactivation of the virus should be $3400 \mu \mathrm{Wscm}^{-2}$ for $90 \%$, and $6600 \mu \mathrm{Wscm}^{-2}$ for an efficiency of $99 \%$ at a wavelength of $253.7 \mathrm{~nm}$.

Furthermore, it is necessary to maximize the probability of hitting the virus with ultraviolet beams. If the virus is not physically isolated, the efficiency of UV-C is very high. The reason for this is the reflection of UV-C waves from the outer surface of the droplet, which reduces its intensity. As the intensity of UV-C waves decreases, the efficiency of virus inactivation within the droplet decreases. The effect of UV-C on virus inactivation within a solid porous particle is not included in this analysis paper.

The liquid droplet is approximated by a sphere of diameter $d_{o}$, which moves at a velocity $v_{o}$ along the annular channel, while within the droplet there is a virus of diameter $d_{\mathrm{v}}$. The total mass flow of fluid entering the ultraviolet disinfection chamber consists of the mass flow of air, droplets and solid porous particles and is

$$
\dot{m}=\dot{m}_{f}+\dot{m}_{\mathrm{dr}}+\dot{m}_{\mathrm{pa}}
$$

that is

$$
1=\frac{\dot{m}_{a}}{\dot{m}}+\frac{\dot{m}_{d}}{\dot{m}}+\frac{\dot{m}_{p}}{\dot{m}}=\varphi_{\mathrm{a}}+\varphi_{\mathrm{d}}+\varphi_{\mathrm{p}}
$$

where $\varphi_{\mathrm{a}}, \varphi_{\mathrm{d}}$ and $\varphi_{\mathrm{p}}$ are the mass ratio of air, droplets and solid porous particles, respectively. The average value of the UV-C intensity in the annular channel established between the 


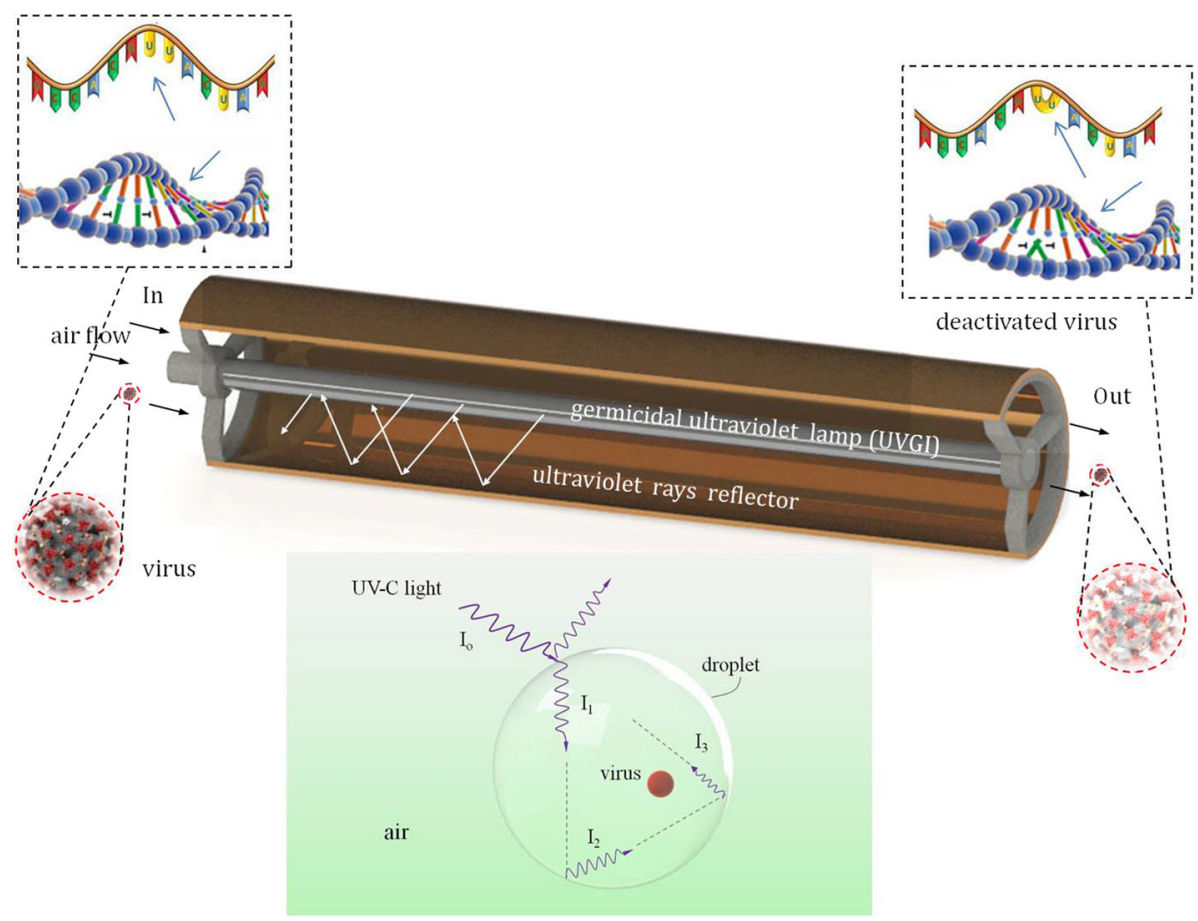

Fig. 3 Destruction of the molecular structure of DNA and RNA by ultraviolet radiation (UV-C). Reflection and refraction of UV-C rays on the surface of a liquid droplet in which the virus is located

surface of the UVGI lamp of radius $R_{\mathrm{L}}$ and the cylindrical housing of radius $R$ can be represented by

$$
\bar{I}\left(R-R_{\mathrm{L}}\right)=\int_{R_{\mathrm{L}}}^{R} I_{o} e^{-r \alpha} \mathrm{d} r,
$$

while the total UV-C dose is distributed in the annular channel

$$
D_{\mathrm{UV}}=\tau_{\mathrm{uv} \cdot d} \bar{I}=\tau_{\mathrm{uv} \cdot d} \frac{1}{R-R_{\mathrm{L}}} \int_{R_{\mathrm{L}}}^{R} I_{o} e^{-r \alpha} \mathrm{d} r
$$

where $\tau$ is exposure time. Within the annular channel, there are air, droplets and solid particles in the mass ratio $\varphi_{\mathrm{a}}, \varphi_{\mathrm{d}}$ and $\varphi_{\mathrm{p}}$, respectively. The total UV-C dose of $D_{U V}$ is distributed in the amounts of $\varphi_{\mathrm{a}} D_{\mathrm{UV}}, \varphi_{\mathrm{d}} D_{\mathrm{UV}}$ and $\varphi_{\mathrm{p}} D_{\mathrm{UV}}$. The effect of UV-C radiation only to viruses within droplets equals, i.e.,

$$
\left(D_{\mathrm{UV}}\right)_{d}=\varphi_{\mathrm{d}} D_{\mathrm{UV}}=\tau_{\mathrm{uv} \cdot d} \bar{I}=\frac{L_{\mathrm{L}}}{v_{o}} \frac{1}{R-R_{\mathrm{L}}} \int_{R_{\mathrm{L}}}^{R} I_{o} e^{-r \alpha} \mathrm{d} r .
$$

In this case, it is considered that the velocity of the droplets of diameter $d_{o}$ is constant and amounts to $v_{o}$, and that during exposure time $\tau$ the droplets pass the length of the UVGI lamp $L_{\mathrm{L}}$. When UV-C waves arrive on the surface of the droplet, as shown in Fig. 3, one part 
of the radiation is reflected, while the other part enters the droplet. The effect of the reflector is to enable the droplet to hit the UV-C wave over the entire outer surface.

The reflection coefficient of the reflector was adopted and is 1 . The intensity of UV-C radiation entering the droplet is reduced by the albedo value of the droplet $(a)$. The albedo of the droplet represents the ratio of reflected UV-C radiation to the radiation that reached its surface and can be calculated based on the following expression,

$$
a=\frac{\left(n_{\text {water }}-n_{\text {air }}\right)^{2}}{\left(n_{\text {water }}+n_{\text {air }}\right)^{2}}
$$

where $n_{\text {water }}$ and $n_{\text {air }}$ are the refractive indexes of water and air, respectively. According to the energy losses of UV-C radiation, it is necessary to provide the required dose of UV-C radiation $D_{\mathrm{UV}}$ from UVGI lamp,

$$
D_{\mathrm{UV}}=(1-a) \phi_{\mathrm{d}} \bar{I} \tau_{\mathrm{uv} \cdot d}=(1-a) \frac{n d_{o}^{3}}{6\left(R^{2}-R_{\mathrm{L}}^{2}\right) \alpha L_{\mathrm{L}}} \frac{\int_{R_{L}}^{R} I_{o} e^{-\alpha r} \mathrm{~d} r}{\left(R-R_{\mathrm{L}}\right)} \frac{L_{\mathrm{L}}}{v_{o}}
$$

where $\alpha$ is Napierian absorption coefficient, and $I_{o}$ is irradiance of UV-C light. The singlestage exponential decay equation for viruses exposed to UV-C light can be presented,

$$
S=\exp \left(-k D_{\mathrm{uv}}\right)
$$

where $S$ is surviving fraction of initial viruses, and $\mathrm{k}$ is standard inactivation UV-C rate. According to Eq. (45), the efficiency of UV-C inactivation of viruses hidden inside the droplets is

$$
\eta_{\mathrm{uv} \cdot d}=1-S=1-\frac{N}{N_{o}}=1-\exp \left(-k D_{\mathrm{uv}}\right)
$$

where $N$ is number of inactivated viruses hidden inside the droplets, and $N_{o}$ is the total number of droplets at the entrance to the UV-C chamber. (The total number of viruses is considered to be equal to the total number of droplets, i.e., one virus per droplet.) Within the droplet, multiple reflections of UV-C waves can occur by the reflection of this wave from the inner surfaces of the droplet in the form of a sphere. Ultraviolet Germicidal Dose DUVC for SARS-CoV was used as a value of $20 \mathrm{mJcm}^{-2}$ for the wavelength values of $254 \mathrm{~nm}$ [17]. For example, the rotavirus requires about $25 \mathrm{mJcm}^{-2}$ of $254 \mathrm{~nm} \mathrm{UV-C} \mathrm{radiation,} \mathrm{but} \mathrm{for}$ adenovirus (Type 40), the value is approximately six times higher $\left(140 \mathrm{mJcm}^{-2}\right)$ [17, 29]. Napierian absorption coefficient $(\alpha)$ for water at a wavelength of $254 \mathrm{~nm}$ is in the amount of $240 \mathrm{~m}^{-1}$. The value of albedo $(a)$ in the reflection of ultraviolet waves (UV-C) from the surface of the water droplet was adopted in the amount of 0.025 , i.e., $2.5 \%$. In this analysis, it was adopted that the UV-C wave passes through the inside of the droplet (diameter $d_{o}$ ) and after reflection from the inner surface hits the meta-virus. The weakening of the UV-C wave intensity after reflection from the inner surface of the droplet is not included in this analysis. paper. The UV-C wave just before entering the surface of the droplet has an intensity of $I_{o}$. Due to the different refractive index of the medium, air-liquid, one part of the intensity of the incident wave is reflected by $I_{r}$, while the other part enters the droplet $I_{\tau}$. The intensity of the transmitted wave $I_{\tau}$ can be so small that even a direct collision with the virus will not inactivate it. On the other hand, the missed UV-C wave of intensity $I_{\tau}$ can be reflected many times from the inner surface of the droplet and thus further reduce its intensity. 


\section{Electrostatic treatment of viruses}

If the virus is inside a porous solid particle, ultraviolet radiation has no possibility of destroying the virus and it is further transported with the particle to the next chamber. If a particle is charged and exposed to negative ions, its transport will be possible to control within the electric field. In order to obtain a large number of negative ions, an electrical system was established as shown in Fig. 4. The voltage between the corona electrode and the anode has the task of establishing the so-called corona discharge between these two electrodes, which will affect the creation of a large number of free electrons. The voltage between the corona electrode and the anode establishes a corona discharge, which affects the creation of a large number of free electrons. The generated electrons move away from the negative electrode (cathode) at high speed and collide with solid porous particles. Although free electrons will cause ionization of surrounding molecules and their transition from an electrically conductive state, the research in this paper is directed toward solid porous particles.

As we move away from the corona electrode, the velocity of the electrons decreases, their kinetic energy weakens, and thus, their ability to ionize air molecules weakens. Also, the charge of solid particles occurs in random collisions of negative molecules, which previously became negative in the collision with electrons of low kinetic energies. In this way, solid
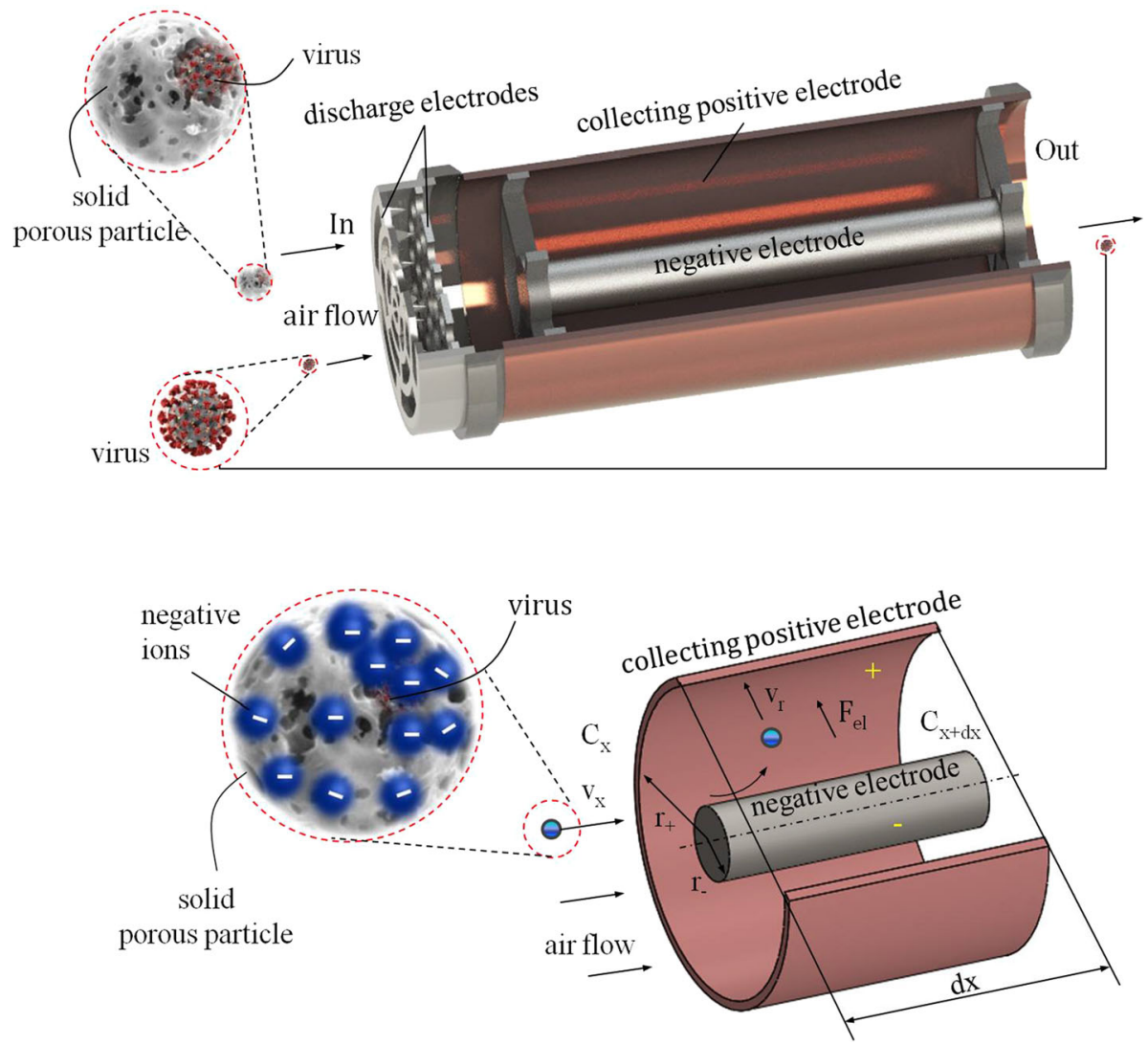

Fig. 4 The hidden and deactivated virus enters the ionization-separation chamber 
porous particles become electrically conductive, i.e., negatively charged. The electronic filling of the porous surface of a particle will last until its surface is saturated with a negative charge. The mass balance of solid porous particles when passing through the ionization-separation chamber at the elementary length of the annular channel, inner $\left(r_{i}\right)$ and outer radius $\left(r_{o}\right)$ can be represented by the equation

$$
\pi u\left(r_{o}^{2}-r_{i}^{2}\right)\left(C_{x}-C_{x+d x}\right)=\pi u\left(r_{o}^{2}-r_{i}^{2}\right) \mathrm{d} C=\frac{\mathrm{d} m_{p \cdot v}}{\mathrm{~d} \tau_{\mathrm{el} \cdot p}}=2 r_{i} \pi C v_{r} \mathrm{~d} x
$$

where $v_{r}$ is the radial component of the particle velocity, and $C_{x}$ and $C_{x+d x}$ are the concentration of porous particles at the site $x$ and $x+d x$, respectively. After separating the variables

$$
\frac{\mathrm{d} C}{C}=\frac{-2 r_{i} v_{r}}{\left(r_{o}^{2}-r_{i}^{2}\right) u} \mathrm{~d} x,
$$

the final expression for the change in the concentration of isolated particles when passing through the ionization-separation chamber is obtained, Eq. 49.

$$
C=C_{o} e^{\frac{-2 r_{i} v_{r}}{\left(r_{o}^{2}-r_{i}^{2}\right) u} x}
$$

The radial component of the velocity of a solid porous particle caused by the action of an electric field between the positive and negative cylindrical electrodes is

$$
v_{r}=\tau_{\mathrm{el} \cdot p} F_{\mathrm{el}}=\frac{\rho_{p} d_{p}^{2}}{18 \mu} C_{\mathrm{Cun}} F_{\mathrm{el}}
$$

where a particle of mass $m_{p}$ and diameter $d_{p}$ which has an accumulated charge $q$ is subjected to an electric field force in the amount of

$$
F_{e l}=\frac{q E_{p}}{m_{p}}=\frac{d_{p}^{2} \pi \varepsilon_{o} K E_{i p} E_{p}}{\frac{1}{6} \rho_{p} d_{p}^{3} \pi}=6 \frac{\varepsilon_{o} K E_{i p} E_{p}}{d_{p} \rho_{p}}
$$

so the combination with Eq. (50) gives the final expression for the radial velocity of the particle $v_{r}$, Eq. (52),

$$
v_{r}=\frac{\rho_{p} d_{p}^{2}}{18 \mu} C_{\mathrm{Cun}} \frac{6 \varepsilon_{o} K E_{i p} E_{p}}{d_{p} \rho_{p}}=\frac{d_{p} \varepsilon_{o}}{\mu} \frac{\varepsilon}{(\varepsilon+2)} E_{p}^{2} C_{\mathrm{Cun}}
$$

where $\varepsilon$ is the dielectric constant of the particle, and $\varepsilon_{o}$ is the dielectric constant of the vacuum, while $\mu$ is the dynamic viscosity of the gas (air). In the previous equations, it was adopted that $E_{\mathrm{ip}} \approx E_{p}$, while the value of Cunningham's correction factor is determined from

$$
C_{\mathrm{cun}}=1+\frac{0.167}{1000 d_{p}}
$$

for particle diameter values $d_{p}$ [m]. After combining Eqs. (49) and (50), the final expression is obtained for reducing the concentration of isolated porous particles when passing through the ionization-separation chamber,

$$
\eta_{\mathrm{el} \cdot p}=1-\frac{C}{C_{o}}=1-\left\{1-\exp \left[\frac{-2 r_{i}}{\left(r_{o}^{2}-r_{i}^{2}\right) u} \frac{d_{p} \varepsilon_{o}}{\mu} \frac{\varepsilon E_{p}^{2} C_{\mathrm{Cun}}}{(\varepsilon+2)} x\right]\right\} \text {. }
$$


5.1 The total efficiency of the three-component system for the treatment of viruses

The overall efficiency $\left(\eta_{\text {tot }}\right)$ of the analyzed system for inactivation and isolation of viruses within droplets and porous solid particles is influenced by the efficiency of each individual chamber. The overall efficiency $\left(\eta_{\text {tot }}\right)_{d}$ of inactivation of viruses within liquid droplets is represented by Eq. (55). This efficiency $\left(\eta_{\text {tot }}\right)_{d}$ is affected by the efficiency of the chamber with infrared heating and ultraviolet radiation. Inside the infrared chamber, thermal inactivation of the virus within the droplet is qualified with $\eta_{I C . d}$.

After the arrival of a drop of reduced diameter (due to infrared heating and evaporation of the same) in the chamber with ultraviolet radiation, the inactivation of viruses will be treated with an ultraviolet germicidal lamp of efficiency $\eta_{\text {uv. } d}$.

$$
\begin{aligned}
\left(\eta_{\mathrm{tot}}\right)_{d} & =1-\frac{C_{\mathrm{el} \cdot d}}{C_{o \cdot d}}=1-\frac{\left(1-\eta_{\mathrm{el} \cdot d}\right) C_{\mathrm{uv} \cdot d}}{C_{o \cdot d}}=1-\frac{\left(1-\eta_{\mathrm{el} \cdot d}\right)\left(1-\eta_{\mathrm{uv} \cdot d}\right) C_{\mathrm{IC} \cdot d}}{C_{o \cdot d}} \\
& =1-\frac{\left(1-\eta_{\mathrm{el} \cdot d}\right)\left(1-\eta_{\mathrm{uv} \cdot d}\right)\left(1-\eta_{\mathrm{IC} \cdot d}\right) C_{o \cdot d}}{C_{o \cdot d}}=1-\left(1-\eta_{\mathrm{el} \cdot d}\right)\left(1-\eta_{\mathrm{uv} \cdot d}\right)\left(1-\eta_{\mathrm{IC} \cdot d}\right)
\end{aligned}
$$

On the other hand, the total efficiency $\left(\eta_{\text {tot }}\right)_{p}$ of the system for inactivation of viruses within solid porous particles depends on the thermal inactivation during infrared heating $\eta_{\text {IC. } p}$ and the efficiency of the ionization-separation chamber $\eta_{\text {el. } p}$, Eq. (56).

$$
\left(\eta_{\mathrm{tot}}\right)_{p}=1-\frac{C_{\mathrm{el} \cdot p}}{C_{o \cdot p}}=1-\left(1-\eta_{\mathrm{IC} \cdot p}\right)\left(1-\eta_{\mathrm{el} \cdot p}\right)
$$

The influence of ultraviolet radiation on the inactivation of viruses within a solid porous particle is not included, and therefore, the efficiency of $\eta_{\text {uv. } p}$ is omitted.

\section{Results and discussion}

6.1 Evaporation of droplets and infrared heating solid porous particles in which the virus is hidden

Immediately before entering the infrared chamber, a diameter of droplets $\left(d_{o}\right)$ is $0.01 \mathrm{~mm}$, $0.03 \mathrm{~mm}$ and $0.05 \mathrm{~mm}$, while the mean velocity of fluid inside the annular cylindrical channel is $0.1 \mathrm{~m} \mathrm{~s}^{-1}$. The droplet temperature is equal to an ambient temperature of $293 \mathrm{~K}$, while the surface temperature of the infrared heat source varies from 650 to $900 \mathrm{~K}$. When moving through the chamber with an infrared heater, the droplets heat up and evaporate, so that their initial diameter decreases. Figure 1 shows the length of the path that the droplets pass in a straight line inside the chamber with the infrared heater, whereby the droplets' diameter is reduced by 10 times $\left(d_{o} / d=10\right)$. Droplets of the largest diameter $(0.05 \mathrm{~mm})$ require a larger heating distance in order to reduce their diameter to a value of $5 \mu \mathrm{m}$.

It is assumed that the virus does not lose its properties during heating and is located in the center of the droplet. For the smallest size of droplet diameter $(0.01 \mathrm{~mm})$, during heating, when the droplet diameter decreases to $1 \mu \mathrm{m}$, the influence of the surface temperature of the infrared heater is minimal. On the other hand, at a constant inlet droplet diameter $\mathrm{d}_{\mathrm{o}}$ of $0.03 \mathrm{~mm}$, its velocities varied in the amounts of $0.1 \mathrm{~m} \mathrm{~s}^{-1}, 0.2 \mathrm{~m} \mathrm{~s}^{-1}$, and $0.3 \mathrm{~m} \mathrm{~s}^{-1}$, as shown in Fig. 5. Heating is performed until the droplet diameter is reduced by a value of 10 times $\left(d_{o} / d=10\right)$, or up to a value of $3 \mu \mathrm{m}$. To achieve this requirement, the longest heating 

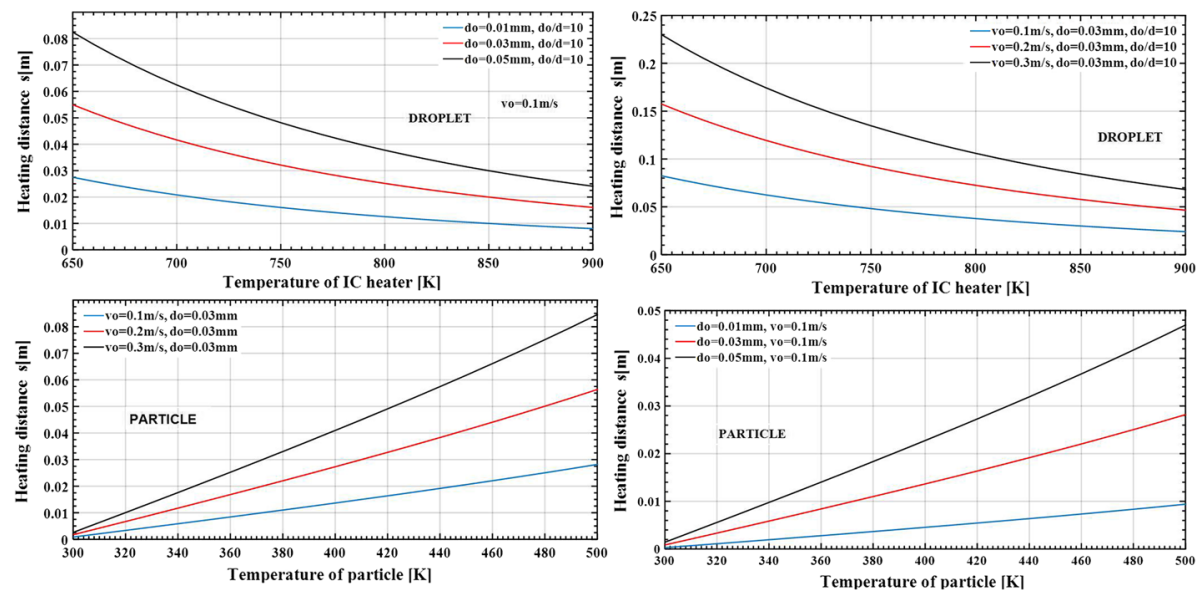

Fig. 5 Evaporation of liquid droplets and infrared heating of solid porous particles, velocity and diameter varied

distance is required for a maximum droplet velocity of $0.3 \mathrm{~m} \mathrm{~s}^{-1}$, with the heat effects of the infrared heater being greatest.

This is due to the shortened heating time of the droplet inside the annular chamber with an infrared heat source.

By heating the solid particle, the virus is also heated, i.e., its temperature approaches the value of the thermal point of inactivation, which can cause the virus to lose its infectivity. For three different diameters of porous solid particles $(0.01 \mathrm{~mm}, 0.02 \mathrm{~mm}$ and $0.03 \mathrm{~mm})$, the particle velocity has a constant value of $0.1 \mathrm{~m} \mathrm{~s}^{-1}$. The porous particle with a diameter of $0.01 \mathrm{~mm}$ has the smallest surface area and volume and thus heats up to a value of $500 \mathrm{~K}$ once it passes $0.098 \mathrm{~m}$. The largest particle diameter of $0.05 \mathrm{~mm}$ passes the greatest distance inside the chamber with an infrared heater, so the rate of temperature rise of this particle is the smallest. Porous particles with a diameter of $0.03 \mathrm{~mm}$ and different velocities of $0.1 \mathrm{~m} \mathrm{~s}^{-1}$, $0.2 \mathrm{~m} \mathrm{~s}^{-1}$ and $0.3 \mathrm{~m} \mathrm{~s}^{-1}$, for their own heating from the initial temperature of $300 \mathrm{~K}$ to $500 \mathrm{~K}$, travel different distances. At a minimum velocity of $0.1 \mathrm{~m} \mathrm{~s}^{-1}$, particles with a diameter of $0.03 \mathrm{~mm}$ need about $0.028 \mathrm{~m}$ for their temperature to rise to $500 \mathrm{~K}$.

\subsection{Thermal inactivation of viruses in droplets and porous solid particles}

Thermal inactivation of the virus depends on the exposure time and temperature of the medium within which the virus is located. Since the temperatures of the droplets and particles are different, the temperature of the their viruses is also different. On the one hand, the temperature of the liquid droplets does not exceed $373 \mathrm{~K}$ since the liquid evaporates and the droplets reduce their volume. On the other hand, the temperature of the porous solid particles rises above $373 \mathrm{~K}$. The initial temperature of the droplet and solid porous particle is $300 \mathrm{~K}$. Since the droplet and the porous solid particle move through the chamber with infrared radiation, the exposure time depends on their velocity. Initial velocities were $0.1 \mathrm{~m} \mathrm{~s}^{-1}, 0.2 \mathrm{~m} \mathrm{~s}^{-1}$ and $0.3 \mathrm{~m} \mathrm{~s}^{-1}$, as shown in Fig. 6, corresponding to exposure times of $3 \mathrm{~s}, 2 \mathrm{~s}$ and $1 \mathrm{~s}$, at a selected infrared chamber length of $0.3 \mathrm{~m}$. For these parameters, thermal inactivation of the virus, at a temperature of $380 \mathrm{~K}$, within the droplet has a maximum value of $1.7 \%(0.017)$ at a maximum exposure time of $3 \mathrm{~s}\left(0.1 \mathrm{~m} \mathrm{~s}^{-1}\right)$. At a minimum exposure time of $1 \mathrm{~s}\left(0.3 \mathrm{~m} \mathrm{~s}^{-1}\right)$, 

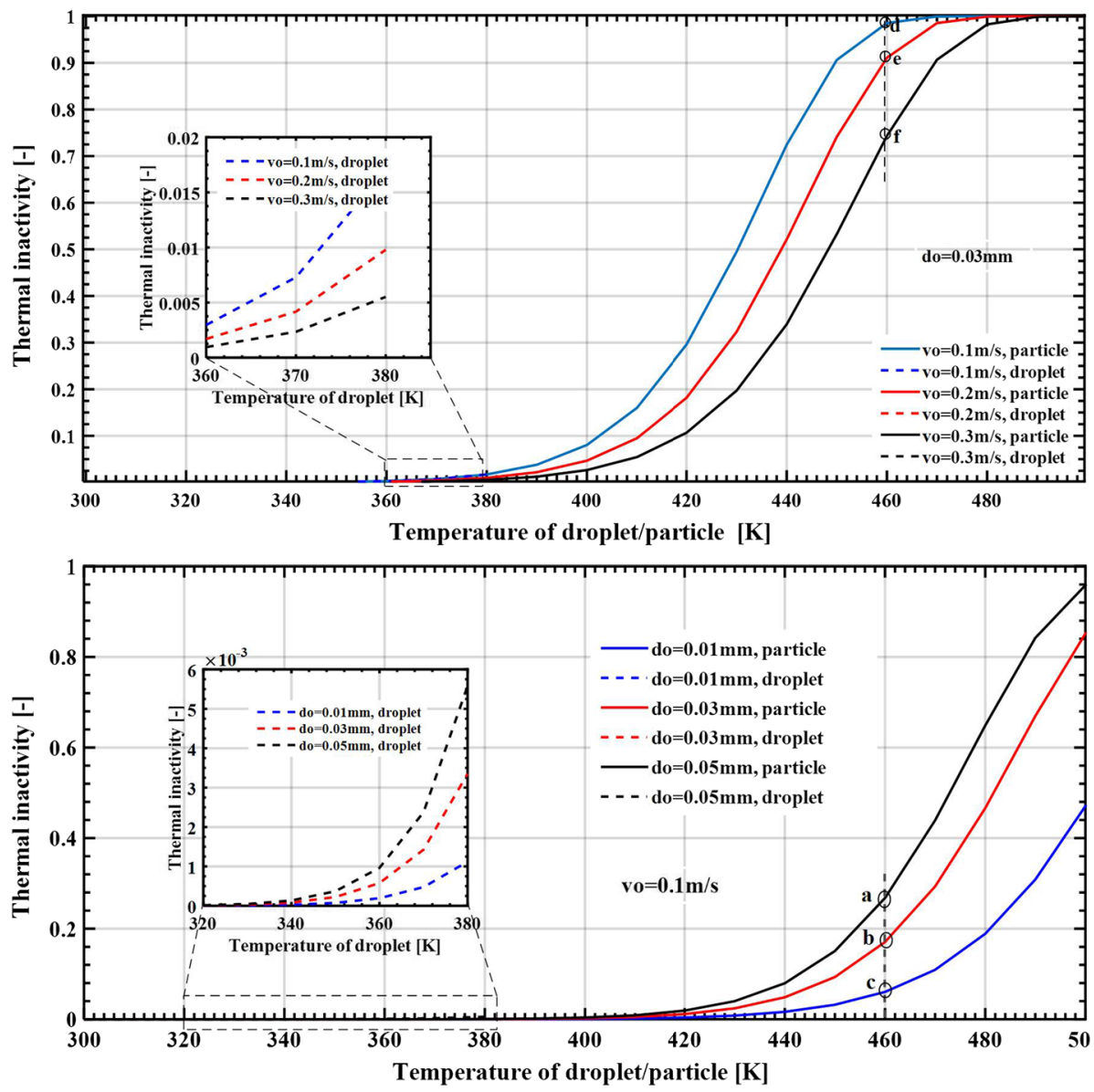

Fig. 6 Thermal inactivation of the virus within droplets and solid porous particles, velocity and diameter varied

thermal inactivation of the virus has a maximum value of $0.52 \%$ (0.0052), as shown in Fig. 6. The average thermal inactivation in the intervals of 0 to $3 \mathrm{~s}$ and 0 to $1 \mathrm{~s}$ is $0.85 \%$ and $0.26 \%$, respectively. At the set values, the thermal inactivation of the virus, as shown in Fig. 6, at a temperature of $460 \mathrm{~K}$ within the solid porous particle, has a mean value of $18 \%$ at a maximum exposure time of $3 \mathrm{~s}\left(0.1 \mathrm{~m} \mathrm{~s}^{-1}, d_{o}=0.03 \mathrm{~mm}\right)$. For example, overall a thermal inactivation at $65{ }^{\circ} \mathrm{C}$, and exposure time of $15 \mathrm{~min}$, for SARS-CoV Strain Urbani [30], was effective to strongly reduce coronavirus infectivity by at least $4 \log 10$. At a minimum exposure time of $1 \mathrm{~s}$, thermal inactivation of the virus has a maximum value of $97 \%$. The second case is based on maintaining a flow velocity rate constant of $0.1 \mathrm{~m} \mathrm{~s}^{-1}$ and varying the particle and droplet diameters in the amounts of $0.01 \mathrm{~mm}, 0.03 \mathrm{~mm}$ and $0.05 \mathrm{~mm}$. The largest diameter of $0.05 \mathrm{~mm}$ absorbs the largest amount of heat, so that thermal inactivation also has the maximum value. 

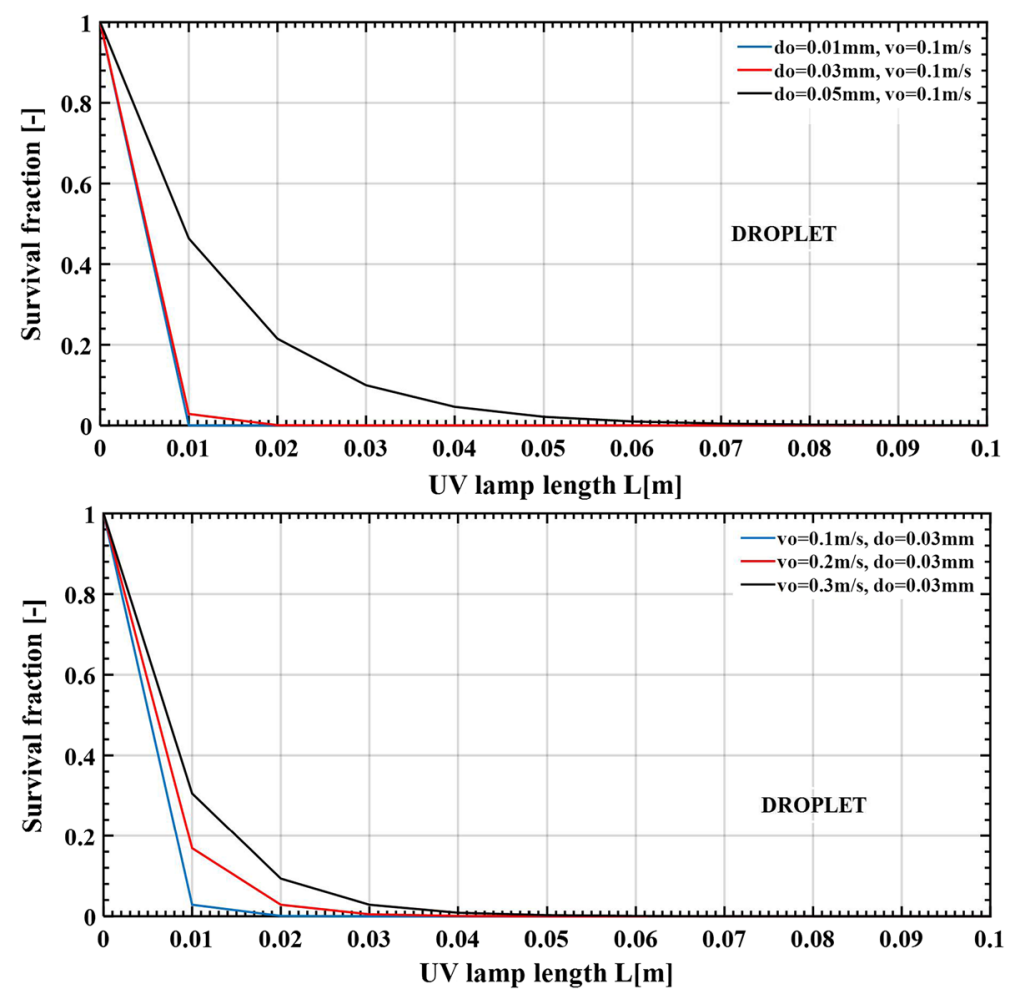

Fig. 7 Survival fraction in the function of UV lamp length, at a constant droplet velocity, velocity and diameter varied

\subsection{UV-C inactivation of viruses within droplets}

The effect of UV-C radiation on viruses within solid porous particles is not included. The analysis was performed on liquid droplets with a diameter of $0.01 \mathrm{~mm}, 0.03 \mathrm{~mm}$ and $0.05 \mathrm{~mm}$ at a speed of $0.1 \mathrm{~m} \mathrm{~s}^{-1}$, as shown in Fig. 7. The outer radius of the cylindrical annular channel is $40 \mathrm{~mm}$, while the radius of the UVGI lamp is $12.7 \mathrm{~mm}$. The irradiance or power $\left(I_{o}\right)$ delivered from the UVGI lamp is $842 \mu \mathrm{Wcm}^{-2}$, while the standard rate constant $(k)$ is $0.001187 \mathrm{~cm}^{-2}$ $\mu \mathrm{J}^{-1}$. The droplet of Napierian absorption coefficient $(\alpha)$ was adopted at a value of 1.5. At the smallest diameter value $(0.01 \mathrm{~mm})$, the shortest length (about $0.01 \mathrm{~m}$ ) of the chamber with UV-C radiation is required, so that the survival fraction has the value 0 , i.e., so that the efficiency of UV-C inactivation of viruses has the value 1, as shown in Fig. 7.

For UV-C inactivation of viruses in droplets of larger diameter, it is necessary to provide a much longer chamber length with UV-C radiation. At the largest droplet diameter, of $0.05 \mathrm{~mm}$, for a survival fraction to be below $47 \%$, and UV-C chamber length of $0.01 \mathrm{~m}$ is required.

\subsection{Ionization-electrostatic inactivation of viruses}

The electrostatic separator efficiency of porous solid particles in which viruses are hidden depends on both the particles' diameter $\left(d_{o}\right)$ and their speed of movement through the annular electrostatic separator. At a constant velocity of $v_{o}=0.1 \mathrm{~m} \mathrm{~s}^{-1}$ along the ionization 

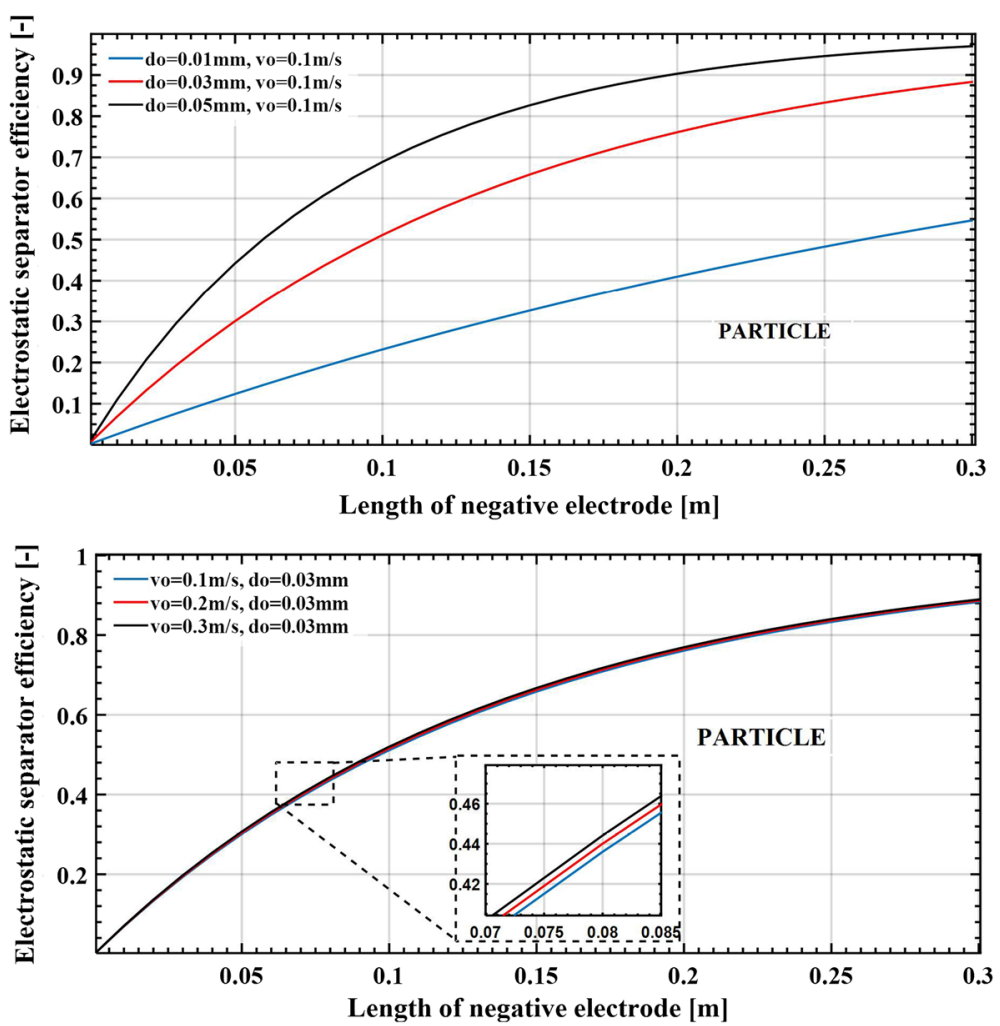

Fig. 8 Electrostatic separator efficiency for different values of porous particle diameters, velocity and diameter varied

electrostatic chamber, the particle diameters $\left(d_{o}\right)$ were of varying sizes $(0.01 \mathrm{~mm}, 0.03 \mathrm{~mm}$ and $0.05 \mathrm{~mm}$ ). The outer radius of the ionization chamber $r_{o}$ is $40 \mathrm{~mm}$, while the inner $r_{i}$ $=14 \mathrm{~mm}$. The voltage between the inner $\left(r_{i}\right)$ and outer electrode $\left(r_{o}\right)$ is $5 \mathrm{kV}$, while the dielectric constant of the particle $\left(\varepsilon_{r}\right)$ is 12 . For the given values, a functional relationship was established between the electrostatic separator efficiency and the length of the negative electrode. The electrostatic separator efficiency (of 97.5\%) reaches the maximum at the separation of the largest particles $(0.05 \mathrm{~mm})$, where the required length of the electrostatic separator is about $0.3 \mathrm{~m}$, as shown in Fig. 8 .

As the particle diameter decreases, the radial velocity of the particle also decreases, and a longer length of the electrostatic separator is necessary in order for the particle to be separated on the separation cylindrical electrode. On the other hand, varying the particle velocity $\left(0.1 \mathrm{~m} \mathrm{~s}^{-1}, 0.2 \mathrm{~m} \mathrm{~s}^{-1}\right.$ and $\left.0.3 \mathrm{~m} \mathrm{~s}^{-1}\right)$ at a constant diameter of $0.03 \mathrm{~mm}$ does not significantly affect the change in the value of electrostatic separator efficiency. It can be seen from the diagram that particles with a diameter of $0.03 \mathrm{~mm}$ at the highest speed of $0.3 \mathrm{~m} \mathrm{~s}^{-1}$ have the fastest increase in the value of electrostatic separator efficiency.

\subsection{Total efficiency of treatment of viruses}

The total efficiency of the three-component system for the treatment of viruses within droplets and solid porous particles is calculated according to Eqs. (55) and (56), respectively. For 

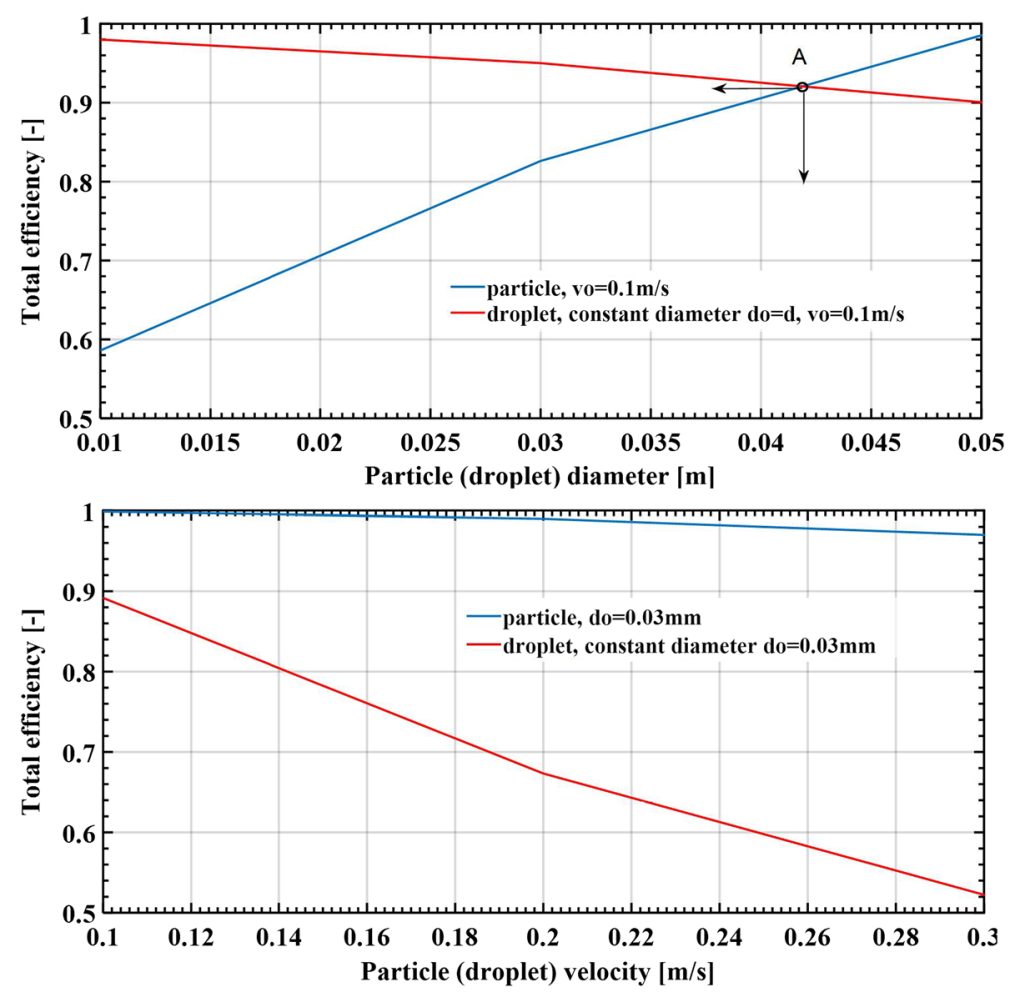

Fig. 9 The total efficiency of the three-component system for the treatment of viruses within droplets and solid porous particles, velocity and diameter varied

two characteristic cases, when the droplet (or particle) diameter and velocity vary, the total efficiency is presented in Fig. 9.

At a constant input velocity $v_{o}$ of $0.1 \mathrm{~m} \mathrm{~s}^{-1}$, due to the increase of the droplet diameter $d_{o}$ to the maximum value of $0.05 \mathrm{~mm}$, the total efficiency decreases by 0.90 . In this case, the change in the diameter of the droplet caused by the evaporation of the liquid is not present, as shown in Fig. 9, because the chamber with the infrared heater is not in operation. If the droplet diameter is reduced by 10 times, the total efficiency of the system for treating viruses within the droplet is approximately constant and is about 0.98 . The multiple increase in total efficiency is not due to the thermal inactivation, but to the increased UV-C inactivation of the virus in droplets. Under the same conditions, the total efficiency of the three-component system in treating viruses hidden within solid porous particles of up to $0.05 \mathrm{~mm}$ diameter increases linearly, up to a value of 0.98 . At a diameter of $0.044 \mathrm{~mm}$ (point A), the total efficiency value is the same (about 0.93 ) for a porous particle and a droplet (which does not change its diameter without evaporation). On the other hand, with the increase of the velocity of the liquid droplet, at a constant diameter of $0.03 \mathrm{~mm}$, the value of total efficiency decreases linearly. The reason for the linear decline in efficiency of the three-component system for the treatment of viruses within droplets (up to $0.03 \mathrm{~mm}$ ) consists of two parts:

- Reduction of exposure time inside the UV-C chamber, with increasing velocity of the droplet; 
- Decrease of UV-C efficiency due to reduced intensity of UV-C radiation entering the droplet.

\section{Conclusions}

The research carried out in this paper aimed to form a three-stage system that would enable the correct treatment of viruses within droplets and solid porous particles. In this paper, viruses were considered to viruses contained within droplets and viruses contained within porous solid particles. A drop of liquid, with its surface, significantly reduces the effectiveness of UV$\mathrm{C}$ treatment of the virus located inside the droplet. The intensity of UV-C radiation decreases due to the reflection on the outer surface of the droplet. The intensity of UV-C radiation can be so weakened that it is unable to inactivate the virus inside the droplet. In the case of virus within a solid porous particle, the effect of UV-C radiation on its deactivation is excluded and was not analyzed. In this analysis, the possibility that the UV-C wave directly hits the virus within the solid porous particle is excluded. For this reason, UV-C inactivation of viruses within porous particles is negligible. In order to increase the efficiency of UV-C inactivation of viruses inside the droplets, a chamber with infrared heating and evaporation of the droplets and heating of solid porous particles was used. When droplets and porous solid particles are heated by infrared radiation, thermal inactivation of viruses can occur, especially those inside solid porous particles. The ionization-separation chamber has the role of electrifying and separating porous solid particles, i.e., inactivating viruses inside these particles with negative ions. The influence of this ionization-separation chamber on the ionization of droplets is not included in this analysis.

Accordingly, the following results can be mentioned:

- Infrared heating and evaporation of droplets increase the efficiency of UV-C inactivation of viruses inside them.

- Infrared radiation is selectively directed toward heating liquid droplets and porous solid particles, while the increase in air temperature is negligible.

- Solid porous particles are significantly heated by the infrared radiation, which causes the appropriate thermal inactivation of viruses inside them.

- Due to low exposure time and low temperature, thermal inactivation of viruses inside liquid droplets is of relatively small value.

- Evaporation of droplets reduces their diameter, which causes a decrease in losses of UV-C radiation when interacting with the outer surface of the droplet.

- Negative ions fill the cavities inside the porous particle and thus block viruses from leaving the porous particle, inactivating them.

- The porous particle in which the virus is deactivated is stopped and separated in the ionization-separation chamber.

Further research, based on the results achieved, will focus on various geometric and process optimizations of the three-component system treatment of viruses, in order to maximize the overall efficiency of their inactivation.

\section{References}

1. C.Y.H. Chao et al., Characterization of expiration air jets and droplet size distributions immediately at the mouth opening. J. Aerosol Sci. 40, 122-133 (2009) 
2. R.S. Papineni, F.S. Rosenthal, The size distribution of droplets in the exhaled breath of healthy human subjects. J. Aerosol Med. 10, 105-116 (1997)

3. L. Morawska et al., Size distribution and sites of origin of droplets expelled from the human respiratory tract during expiratory activities. J. Aerosol Sci. 40, 256-269 (2009)

4. L. Liu, J. Wei, Y. Li, A. Ooi, Evaporation and dispersion of respiratory droplets from coughing. Indoor Air 27, 179 (2017). https://doi.org/10.1111/ina.12297

5. R.R. Netz, Mechanisms of airborne infection via evaporating and sedimenting droplets produced by speaking. J. Phys. Chem. B 124(33), 7093-7101 (2020). https://doi.org/10.1021/acs.jpcb.0c05229

6. J. Redrow, S. Mao, I. Celik, J.A. Posada, Z.-G. Feng, Modeling the evaporation and dispersion of airborne sputum droplets expelled from a human cough. Build. Environ. 46, 2042 (2011). https://doi.org/10.1016/ j.buildenv.2011.04.011

7. H. Laude, Thermal inactivation studies of a coronavirus, transmissible gastroenteritis virus. J. Gen. Virol. 56, 235e40 (1981)

8. Batejat C, Grassin Q, Manuguerra J-C, Leclercq I., 2020. Heat inactivation of the Severe Acute Respiratory Syndrome Coronavirus 2. bioRxiv:https://doi.org/10.1101/2020.05.01.067769.

9. G. Kampf, A. Voss, S. Scheithauer, Inactivation of coronaviruses by heat. J. Hosp. Infect. 105(2), 348-349 (2020). https://doi.org/10.1016/j.jhin.2020.03.025

10. S. Firquet, S. Beaujard, P.-E. Lobert, F. Sané, D. Caloone, D. Izard, D. Hober, Viruses contained in droplets applied on warmed surface are rapidly inactivated. Microbes Environ. 29, 408-412 (2014)

11. C.J. Hurst, W.H. Benton, A. McClellan, Thermal and water source effects upon the stability of enteroviruses in surface freshwaters. Can. J. Microbiol. 35, 474-480 (1989)

12. Y.N. Lee, L.K. Chen, H.C. Ma, H.H. Yang, H.P. Li, S.Y. Lo, Thermal aggregation of SARS-CoV membrane protein. J. Virol. Methods 129, 152e61 (2005)

13. H.F. Rabenau, J. Cinatl, B. Morgenstern, G. Bauer, W. Preiser, H.W. Doerr, Stability and inactivation of SARS coronavirus. Med. Microbiol. Immunol. 194, 1e6 (2005)

14. E.I. Budowsky et al., Principles of selective inactivation of viral genome: I: UV-induced inactivation of influenza virus. Arch. Virol. 68(3-4), 239-247 (1981)

15. S. Zafna et al., Accidental exposure to UV radiation produced by germicidal lamp: case report and risk assessment. Photochem. Photobiol. 88(4), 1001-1004 (2012)

16. K. Narita et al., 222-nm UVC inactivates a wide spectrum of microbial pathogens. J. Hosp. Infect. (2020). https://doi.org/10.1016/j.jhin.2020.03.030

17. W.J. Kowalski, Ultraviolet Germicidal Irradiation Handbook: UVGI for Air and Surface Disinfection (Springer, New York, 2009)

18. N.G. Reed, The history of ultraviolet germicidal irradiation for air disinfection. Public Health Rep. 125, 15-27 (2010)

19. S.Y. Jiang, A. Ma, S. Ramachandran, Negative air ions and their effects on human health and air quality improvement. Int. J. Mol. Sci. 19(10), 2966 (2018)

20. E.W. Kellogg, Air ions: Their possible biological significance and effects. J. Bioelectr. 3(1-2), 119-136 (1984)

21. M. Hagbom, J. Nordgren, R. Nybom, K.O. Hedlund, H. Wigzell, L. Svensson, Ionizing air affects influenza virus infectivity and prevents airborne-transmission. Sci. Rep. 5, 11431 (2015)

22. B.W. Mitchell, D.J. King, Effect of negative air ionization on airborne transmission of Newcastle disease virus. Avian Dis. 38, 725-732 (1994)

23. R.K. Gast, B.W. Mitchell, P.S. Holt, Application of negative air ionization for reducing experimental airborne transmission of Salmonella enteritidis to chicks. Poult. Sci. 78, 57-61 (1999)

24. E.M. Kettleson et al., Airborne virus capture and inactivation by an electrostatic particle collector. Environ Sci Technol. 43, 5940-5946 (2009)

25. M. Flury, S. Aramrak, Role of air-water interfaces in colloid transport in porous media: a review, Water Resour. Res. 53, 5247-5275 (2017). https://doi.org/10.1002/2017WR020597

26. S.A. Bradford, Y. Wang, H. Kim, S. Torkzaban, J. Simunek, Modeling microorganism transport and survival in the subsurface. J. Environ. Qual. 43, 421-440 (2014)

27. P. Sharma, M. Flury, J. Zhou, Detachment of colloids from a solid surface by a moving air-water interface. J. Colloid Interface Sci. 326, 143-150 (2008)

28. T.R. Marrero, E.A. Mason, Gaseous diffusion coefficients. J. Phys. Chem. Ref. Data 1, 3-118 (1972). https://doi.org/10.1063/1.3253094,435

29. G. Chevrefils, É. Caron, UV dose required to achieve incremental Log inactivation of bacteria, protozoa and viruses. IUVA News 8(1), 38-45 (2006)

30. M.E. Darnell, D.R. Taylor, Evaluation of inactivation methods for severe acute respiratory syndrome coronavirus in noncellular blood products. Transfusion 46, 1770e7 (2006) 